\title{
Self-Reported Head Injury and Risk of Late-Life Impairment and AD Pathology in an AD Center Cohort
}

\author{
Erin L. Abner ${ }^{a, d}$ Peter T. Nelson ${ }^{a, b} \quad$ Frederick A. Schmitt ${ }^{a}$ c \\ Steven R. Browning ${ }^{d}$ David W. Fardo ${ }^{a}$ e Lijie Wan $^{f}$ Gregory A. Jicha ${ }^{a, c}$ \\ Gregory E. Cooper ${ }^{i}$ Charles D. Smith ${ }^{a}$ c Allison M. Caban-Holt ${ }^{a}, g$ \\ Linda J. Van Eldik ${ }^{a}$ h Richard J. Kryscio ${ }^{a}, e^{e} f$ \\ a University of Kentucky Alzheimer's Disease Center, Sanders-Brown Center on Aging, \\ Departments of ${ }^{b}$ Pathology, ${ }^{c}$ Neurology, ${ }^{d}$ Epidemiology, ${ }^{e}$ Biostatistics, ${ }^{f}$ Statistics, \\ ${ }^{g}$ Behavioral Sciences, and ${ }^{h}$ Anatomy and Neurobiology, University of Kentucky, and \\ 'Baptist Neurology Center, Lexington, Ky., USA
}

\section{Key Words}

Head injury · Alzheimer's disease $\cdot$ Neuropathology $\cdot$ Dementia $\cdot$ Cognition

\begin{abstract}
Aims: To evaluate the relationship between self-reported head injury and cognitive impairment, dementia, mortality, and Alzheimer's disease (AD)-type pathological changes. Methods: Clinical and neuropathological data from participants enrolled in a longitudinal study of aging and cognition $(n=649)$ were analyzed to assess the chronic effects of self-reported head injury. Results: The effect of self-reported head injury on the clinical state depended on the age at assessment: for a 1-year increase in age, the OR for the transition to clinical mild cognitive impairment (MCI) at the next visit for participants with a history of head injury was 1.21 and 1.34 for the transition from MCI to dementia. Without respect to age, head injury increased the odds of mortality $(\mathrm{OR}=1.54)$. Moreover, it increased the odds of a pathological diagnosis of $A D$ for men $(O R=1.47)$ but not women $(O R=1.18)$. Men with a head injury had higher mean amyloid plaque counts in the neocortex and entorhinal cortex than men without. Conclusions: Self-reported head injury is associated with earlier onset, increased risk of cognitive impairment and dementia, increased risk of mortality, and AD-type pathological changes.

(C) 2013 S. Karger AG, Basel
\end{abstract}


Abner et al.: Self-Reported Head Injury and Risk of Late-Life Impairment and AD Pathology in an AD Center Cohort

\section{Introduction}

Although there have been many careful studies of head injury as a risk factor for dementia, the literature on head injury and dementia has been limited since none of the longitudinal studies have used autopsy-confirmed diagnoses or examined neuropathological data. This is significant because an estimated $20-30 \%$ of cases clinically diagnosed with Alzheimer's disease (AD) have additional pathologies or no AD pathology [1]. The current study reexamines the association between self-reported head injury, risk of clinical dementia, and AD pathology using data from participants with detailed longitudinal cognitive assessments, as well as a subset of participants with quantitative neuropathological data.

\section{Background}

Autopsy-based studies of head trauma have reported that neurodegenerative pathology appears to be linked to injuries sustained many years earlier. Increases in the number of $\beta$-amyloid precursor protein-positive neurons were observed in cases of isolated severe head injury compared to age-matched controls [2]. Long-term increases in $\tau$ and $\beta$-amyloid, as well as increased neuroinflammatory response and white matter degradation have been noted in patients with a history of a single head injury sustained up to 47 years before death $[3,4]$. Both acute and chronic axonal injuries, including accumulation of proteins associated with neurodegenerative diseases, have been observed in individuals with a history of head injury $[5,6]$. However, etiological links have not been solidly established in terms of how the brain trauma manifests neuropathologically.

Studies of chronic traumatic encephalopathy (CTE) have involved autopsy series [7-9]. CTE implies a history of repeated brain injury and is a progressive illness characterized by deficits in motor skills and cognition, and increased psychiatric symptoms such as depression, irritability, and aggression [10]. CTE pathology is marked by increased $\tau$, and in some cases, TAR DNA-binding protein 43 [8] with or without diffuse $\beta$-amyloid deposits [11]. Thus, CTE has both a clinical and neuropathological overlap with $\mathrm{AD}$, but the two are distinct diseases in terms of severity, anatomical distribution, and other manifestations of brain pathology.

Epidemiological studies of head injury as a risk for dementia have yielded conflicting evidence. Kondo et al. [12] conducted a case-control study of 120 elderly Japanese individuals matched for age and sex and evaluated multiple lifestyle and medical history factors as risks for AD [12]. Self-reported head injury with loss of consciousness (LOC) was associated with an increased odds of AD (OR $=5.5,95 \%$ CI 2.8-13.8). A meta-analysis of 15 case-control studies found an overall increased odds of AD for those with a history of head injury with LOC prior to $\mathrm{AD}$ onset (pooled $\mathrm{OR}=1.58,95 \% \mathrm{CI} 1.21-2.06$ ), despite the fact that the odds of $\mathrm{AD}$ were increased for men (OR $=2.29,95 \% \mathrm{CI} 1.47-3.58)$ but not for women $\mathrm{OR}=0.91,95 \% \mathrm{CI}$ $0.56-1.47$ ] [13]. However, injury severity was not considered in the meta-analysis, and AD diagnosis was not autopsy-confirmed.

Results from cohort studies have also been inconsistent (table 1), which likely reflects differences in exposure assessment, follow-up time, loss to follow-up, study populations, and covariates selected for adjustment in calculating risk estimates. Two large prospective studies - the Rotterdam Study [14] and Adult Changes in Thought [15] - found no increased risk of dementia or AD associated with a past head injury. Data from the smaller Betula study [16], by contrast, revealed an increased risk for participants with a self-reported mild head injury and APOE $\varepsilon 4$. Results from a Cambridge city study [17] found no increased risk of incident dementia associated with a history of head injury in a community-dwelling population aged 75 years and older after 2.4 years of follow-up. 
Abner et al.: Self-Reported Head Injury and Risk of Late-Life Impairment and AD

Pathology in an AD Center Cohort

Table 1. Summary of cohort studies of head injury and dementia

\begin{tabular}{|c|c|c|c|c|c|c|}
\hline Study & Type & $\mathrm{n}$ & $\begin{array}{l}\text { Effect estimate(s) for dementia } \\
\text { risk }\end{array}$ & Exposure assessment & $\begin{array}{l}\text { Head } \\
\text { injury } \\
\text { prevalence, } \\
\%\end{array}$ & Limitations \\
\hline $\begin{array}{l}\text { Rotterdam study } \\
{[14]}\end{array}$ & $\mathrm{P}$ & 6,645 & $\mathrm{RR}=0.8,95 \%$ CI $0.4-1.9$ & $\begin{array}{l}\text { Self-report to study } \\
\text { physician }\end{array}$ & 12.0 & $\begin{array}{l}2 \text { years of follow-up, } \\
\text { inclusion of younger } \\
\text { adults ( } \leq 60 \text { years), dx } \\
\text { not autopsy-confirmed }\end{array}$ \\
\hline $\begin{array}{l}\text { Adult changes } \\
\text { in thought [15] }\end{array}$ & $\mathrm{P}$ & 4,225 & $\begin{array}{l}\text { Age at injury <25: TR = } 1.02, \\
95 \% \text { CI } 0.87-1.20 \\
\text { Age at injury } 25-54: \text { TR }=1.04 \text {, } \\
95 \% \text { CI } 0.78-1.38 \\
\text { Age at injury } 55+: \text { TR = } 1.06 \text {, } \\
\text { 95\% CI } 0.81-1.39\end{array}$ & $\begin{array}{l}\text { Self-report via } \\
\text { structured interview by } \\
\text { study personnel }\end{array}$ & 15.9 & $\begin{array}{l}\text { dx not autopsy- } \\
\text { confirmed }\end{array}$ \\
\hline $\begin{array}{l}\text { Plassman et al. } \\
\text { [18] }\end{array}$ & $\mathrm{R}$ & 1,776 & $\begin{array}{l}\text { Mild injury: HR = 0.76, } \\
\text { 95\% CI 0.18-3.29 } \\
\text { Moderate injury: HR = 2.32, } \\
\text { 95\% CI 1.04-5.17 } \\
\text { Severe injury: HR = 4.51, } \\
\text { 95\% CI 1.77-11.47 }\end{array}$ & $\begin{array}{l}\text { Review of military } \\
\text { medical records } \\
\text { between } 1944 \text { and } 1945\end{array}$ & $\mathrm{n} / \mathrm{a}$ & $\begin{array}{l}\text { Head trauma sustained } \\
\text { outside military service } \\
\text { not accounted for, dx not } \\
\text { autopsy-confirmed }\end{array}$ \\
\hline $\begin{array}{l}\text { Williams et al. } \\
\text { [19]; Nemetz } \\
\text { et al. [20] }\end{array}$ & $\mathrm{R}$ & 1,283 & $\begin{array}{l}\mathrm{SIR}=1.2,95 \% \text { CI } 0.8-1.7 ; \\
\text { median onset shortened by } \\
8 \text { years }(\mathrm{p}=0.0015)\end{array}$ & $\begin{array}{l}\text { Review of Mayo Clinic } \\
\text { medical records for } \\
\text { cases with traumatic } \\
\text { brain injury diagnosed } \\
\text { between } 1935 \text { and } 1984\end{array}$ & $\mathrm{n} / \mathrm{a}$ & $\begin{array}{l}\text { Head trauma not } \\
\text { requiring hospital visit } \\
\text { not captured, dx based } \\
\text { on medical records not } \\
\text { clinical interview, dx not } \\
\text { autopsy-confirmed }\end{array}$ \\
\hline $\begin{array}{l}\text { Sundström } \\
\text { et al. [16] }\end{array}$ & $\mathrm{P}$ & 543 & $\begin{array}{l}\text { Without APOE } \varepsilon 4: \text { OR }=0.9 \text {, } \\
95 \% \text { CI } 0.4-1.8 \\
\text { With APOE } \varepsilon 4: \text { OR = 5.2, } \\
95 \% \text { CI } 2.0-14.0\end{array}$ & $\begin{array}{l}\text { Affirmative response to } \\
\text { questionnaire item 'have } \\
\text { you ever suffered a head } \\
\text { injury which required } \\
\text { medical care?' }\end{array}$ & 13.1 & $\begin{array}{l}\text { Inclusion of younger } \\
\text { adults ( } \leq 60 \text { years), } \mathrm{dx} \\
\text { not autopsy-confirmed }\end{array}$ \\
\hline $\begin{array}{l}\text { Brayne et al. } \\
{[17]}\end{array}$ & $\mathrm{P}$ & 376 & $\begin{array}{l}\text { All dementia OR = } 1.2, \\
95 \% \text { CI } 0.3-4.2 ; \mathrm{AD} \mathrm{OR}=1.9 \\
95 \% \text { CI } 0.4-2.3\end{array}$ & Informant report & 9.0 & $\begin{array}{l}2.4 \text { years of follow-up, } \mathrm{dx} \\
\text { not autopsy confirmed }\end{array}$ \\
\hline WHICAP [21] & $\mathrm{P}$ & 271 & $\begin{array}{l}\text { LOC }<5 \text { min: } \mathrm{RR}=1.7 \\
95 \% \text { CI } 0.4-7.5 \\
\mathrm{LOC} \geq 5 \text { min: } \mathrm{RR}=11.2, \\
95 \% \text { CI } 2.3-59.8\end{array}$ & $\begin{array}{l}\text { Self-report via } \\
\text { structured risk factor } \\
\text { interview at baseline } \\
\text { and during a one-time } \\
\text { physician interview }\end{array}$ & 10.0 & $\begin{array}{l}\text { Few participants with } \\
\text { head injury in the } \\
\text { sample, dx not autopsy- } \\
\text { confirmed }\end{array}$ \\
\hline
\end{tabular}

$\mathrm{P}=$ Prospective; $\mathrm{R}$ = retrospective; $\mathrm{dx}=$ clinical diagnosis; $\mathrm{RR}=$ relative risk; $\mathrm{TR}$ = time ratio; $\mathrm{HR}$ = hazard ratio; $\mathrm{SIR}=$ standardized incidence ratio.

Retrospective cohort studies have reported that head injury is an independent risk factor for $\mathrm{AD}$ or decreases time to dementia onset. Plassman et al. [18] reviewed military medical records and compared men who had been hospitalized with a closed head injury to those with an unrelated condition. All-cause dementia, and AD specifically, was associated with both moderate and severe, but not mild, injuries.

A retrospective review of medical records from residents of Olmsted County, Minn., USA, who were treated for head trauma and were over the age of 40 years at the time of their last medical assessment, showed no increased risk of AD or all-cause dementia [19, 20]. However, when time to onset was used as the outcome, persons with a head trauma developed AD a median of 8 years earlier than expected when compared to the age-based incidence of AD in 
Fig. 1. Flow diagram of included BRAiNS cohort participants.

Abner et al.: Self-Reported Head Injury and Risk of Late-Life Impairment and AD Pathology in an AD Center Cohort

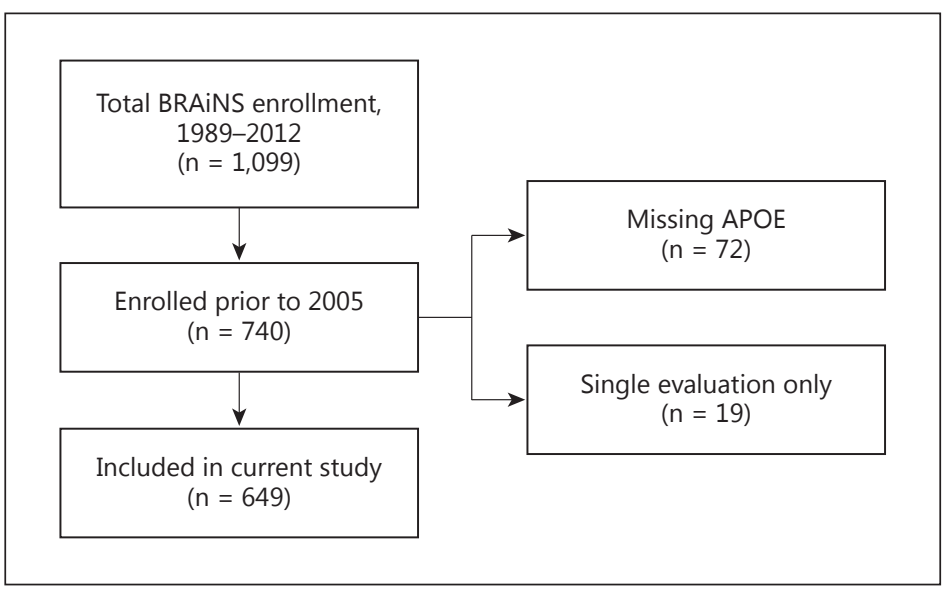

the total county population. Similarly, a prospective cohort study of Manhattan, N.Y., USA residents found that after 5 years of follow-up, a history of head injury with LOC within the preceding 30 years was associated with an earlier onset of $\mathrm{AD}$, and the effect was stronger for those reporting an LOC of at least $5 \mathrm{~min}$ [21].

\section{Methods}

Subjects

Subjects of this study are volunteers from Biologically Resilient Adults in Neurological Studies (BRAiNS) at the University of Kentucky Alzheimer's Disease Center, a longitudinal cohort of approximately 1,100 individuals established in 1989 with ongoing recruitment [22]. The cohort comprises a convenience sample of older adults (age $\geq 60$ years) from central Kentucky, USA. BRAiNS exclusion criteria include prevalent neurological, psychiatric, and disabling medical disorders, as well as prevalent dementing illness (see Schmitt et al. [22] for a detailed description of recruitment and study procedures). The subjects in the current analysis ( $n=649$ ) were enrolled between 1989 and 2004, evaluated at least two times, and had APOE genotyping available (fig. 1). They undergo annual cognitive and clinical assessments and donate their brains upon death.

The participants who died and underwent autopsy were included in a subset analysis. Of these, 17 cases were excluded from further analysis because quantitative neuropathology data were unavailable. An additional 15 were excluded from further analysis due to the presence of diffuse Lewy body disease, leaving $238 / 270$ for inclusion in quantitative analyses of the AD-type neuropathological burden. All enrollees were cognitively normal at study entry, and all research activities were approved by the University of Kentucky Institutional Review Board. Each participant provided written informed consent.

\section{Statistical Analysis}

Multistate Markov Chain

To test the hypothesis that a self-reported history of head injury promotes transition to impaired cognition, a multistate Markov chain was fit to the data. Multistate Markov chains are attractive for modeling cognitive decline [23-26], and they allow for the inclusion of competing risks for the outcome of interest (allcause dementia) as participants who die or drop out before dementia onset may bias analyses [27]. Participants were retrospectively classified into states at each assessment: (1) normal cognition, (2) test-based amnestic mild cognitive impairment $\left(\mathrm{aMCI}_{\mathrm{TB}}\right)$, (3) test-based mixed $\mathrm{MCI}\left(\mathrm{mMCI}_{\mathrm{TB}}\right)$, (4) clinical consensusbased MCI ( $\mathrm{MCI}_{\mathrm{CC}}$ ), (5) dementia (all-cause), (6) dropout without dementia, and (7) death without dementia. The classification method has been described in detail previously [23, 24]. Briefly, normal cognition represents the absence of any impairments on cognitive testing as well as the absence of any clinical diagnosis of MCI or dementia; test-based MCI indicates at least one observed score of at least 1.5 standard deviations below the expected score for age based on the baseline performance of the entire normal cohort on tests of episodic memory $\left(\mathrm{aMCI} \mathrm{TB}_{\mathrm{TB}}\right)$ or language and executive function $\left(\mathrm{mMCI}_{\mathrm{TB}}\right) ; \mathrm{MCI}_{\mathrm{CC}}$ indicates a diagnosis of $\mathrm{MCI}$ 
Abner et al.: Self-Reported Head Injury and Risk of Late-Life Impairment and AD

Pathology in an AD Center Cohort

based on criteria used by the National Alzheimer's Coordinating Center's Uniform Data Set [28], and dementia indicates a clinical diagnosis of dementia based on DSM-IV criteria [29].

A multistate Markov chain with 4 transient states (normal cognition, $\mathrm{aMCI}_{\mathrm{TB}}, \mathrm{mMCI}_{\mathrm{TB}}$, and $\mathrm{MCI}_{\mathrm{CC}}$ ) and 3 absorbing states (death, dementia, and dropout) was used. An individual may move freely among the transient states, but once an absorbing state is reached that individual's follow-up ends for the purposes of the analysis. The model estimates the log-odds of a one-step transition between any two adjacent assessments, here called the 'prior state' and the 'current state', versus remaining in or returning to a 'base state'.

To account for within-subject correlation, subject-specific random effects were included in the model as described in Abner et al. [23] via PROC NLMIXED in SAS/STAT 9.3 ${ }^{\circledR}$ [30]. Observed transitions are assumed to have occurred on the visit date. Predictor variables stayed in the model only if they significantly affected any one-step transition probability.

\section{Risk Factors}

History of head injury was determined from participant responses to the intake interview questions, 'Have you ever been knocked unconscious? If yes, how long were you unconscious, when did it happen, and how did it happen?'. The participants who reported LOC of any duration, or a diagnosis of concussion without LOC, were coded as positive for history of head injury. Where head injury was reported, approximate age at injury, LOC duration ( $<5 \mathrm{~min}, \geq 5 \mathrm{~min}$ ), and external cause of the injury were recorded. The participants who described their LOC as 'a few moments', 'a few minutes', 'momentarily', or whose LOC duration was not described $(n=6)$ were coded as $<5$ min. Five minutes was chosen for dichotomization based on the increased risk of dementia associated with an LOC of longer than $5 \mathrm{~min}$ as reported by Schofield et al. [21]. Additional injury data were derived from interviews conducted longitudinally by study clinicians. Thus, head injury was treated as a time-varying factor. Two-way interactions between head injury and sex as well as age were tested for inclusion in the model. A two-way interaction between head injury and APOE $\varepsilon 4$ could not be evaluated due to sample size limitations.

Other risk factors of interest include age at assessment (centered at 79 years), sex, education $(\leq 12$ years, $>12$ years), APOE $\varepsilon 4$ carrier status ( $\geq 1 \varepsilon 4$ allele vs. no $\varepsilon 4$ alleles), family history of dementia (firstdegree relatives only), baseline hypertension (yes vs. no), and baseline smoking history (never, 0-10 packyears, 10-20 pack-years, 20+ pack-years).

Generalized Linear Regression

Multivariate analysis of covariance (MANCOVA) was used to test the hypothesis that self-reported history of head injury leads to increased AD-type pathology in the neocortex and medial temporal lobe, both of which have been identified as sites with increased $\beta$-amyloid precursor protein-positive neurons following head injury [2,31]. MANCOVAs estimating the effect of head injury on mean diffuse (DPs) and neuritic plaque counts (NPs) as well as mean neurofibrillary tangle counts (NFTs) in the neocortex (frontal, temporal, parietal, and occipital regions) and medial temporal lobe (entorhinal cortex, amygdala, hippocampus CA1, and subiculum) were fit using PROC GLM in SAS/STAT 9.3. Glial tangle data were not available. Logistic regression was used to test the hypothesis that head injury increases the odds of AD pathology. All models included age at death and indicators for APOE $\varepsilon 4$ status, male sex, presence of at least mild cerebral amyloid angiopathy (which is associated with increased amyloid plaque burden), and whether clinical dementia was observed before death. Two-way interactions between head injury and age at death, APOE $\varepsilon 4$, and sex were also tested. Statistical significance for all analyses was set at $\alpha=0.05$.

Pathological Assessments

AD-positive pathology refers to cases with Braak stage III-VI and with moderate or severely dense neuritic amyloid plaques according to CERAD criteria [32]. Neuropathological counting metrics and methods were exactly as described previously [33, 34].

\section{Results}

Clinical Data

Study participants contributed an average of 10.4 longitudinal assessments (median = 10 , range $=2-22$ ), with an average of 13 months between assessments (table 2). During the 
Table 2. Characteristics of included participants from the BRAiNS cohort (enrolled in the study between 1989 and 2004)

\begin{tabular}{llll}
\hline Characteristic & $\begin{array}{l}\text { All subjects } \\
(\mathrm{n}=649)\end{array}$ & $\begin{array}{l}\text { Head injury } \\
(\mathrm{n}=166)\end{array}$ & $\begin{array}{l}\text { No head injury } \\
(\mathrm{n}=483)\end{array}$ \\
\hline Age at entry, years & $72.9 \pm 7.4$ & $72.8 \pm 7.4$ & $73.0 \pm 7.4$ \\
Female & 63.9 & 50.0 & 68.7 \\
Family history of dementia & 38.7 & 36.8 & 39.3 \\
At least one APOE 8 allele & 30.4 & 29.5 & 30.6 \\
>12 years of education & 86.9 & 91.0 & 85.5 \\
History of hypertension at entry & 38.2 & 39.8 & 37.7 \\
Smoking history at entry & & & \\
$\quad$ Never smoked & 49.2 & 43.4 & 51.1 \\
$\quad$ >-10 pack-years & 10.3 & 9.6 & 7.6 \\
$\quad$ 10-20 pack-years & 8.3 & 9.6 & 30.4 \\
$\quad$ More than 20 pack-years & 32.2 & 37.4 & $10.4 \pm 4.6$ \\
Number of assessments & $10.3 \pm 4.7$ & $10.2 \pm 4.8$ & $1.1 \pm 0.4$ \\
Time between assessments, years & $1.1 \pm 0.3$ & $1.1 \pm 0.2$ & \\
\hline
\end{tabular}

Values are means \pm SD or percentages.

Table 3. One-step transition matrix

\begin{tabular}{|c|c|c|c|c|c|c|c|}
\hline \multirow[t]{2}{*}{ Prior state } & \multicolumn{7}{|l|}{ Current state } \\
\hline & normal & $\mathrm{aMCI}_{\mathrm{TB}}$ & $\mathrm{mMCI}_{\mathrm{TB}}$ & $\mathrm{MCI}_{\mathrm{CC}}$ & dementia & dropout & death \\
\hline Normal & $2,634(69.1)$ & $524(13.8)$ & $464(12.2)$ & $40(1.1)$ & $15(0.4)$ & $33(0.9)$ & $101(2.7)$ \\
\hline $\mathrm{aMCI}_{\mathrm{TB}}$ & 497 (57.6) & 172 (19.9) & $129(15.0)$ & $23(2.7)$ & $9(1.0)$ & 13 (1.5) & $20(2.3)$ \\
\hline $\mathrm{mMCI}_{\mathrm{TB}}$ & $404(30.7)$ & $97(7.4)$ & $601(45.7)$ & $66(5.0)$ & $35(2.7)$ & $30(2.3)$ & $80(6.2)$ \\
\hline $\mathrm{MCI}_{\mathrm{CC}}$ & & & & $154(61.4)$ & $50(19.9)$ & $16(6.4)$ & $31(12.4)$ \\
\hline
\end{tabular}

Number of assessments ( $\%$ of prior visit state). Total subjects: $n=649$.

study period, 386 (59.5\%) participants transitioned to $\mathrm{aMCI}_{\mathrm{TB}}$ at least one time, $398(61.3 \%)$ transitioned to $\mathrm{mMCI}_{\mathrm{TB}}$ at least one time, $129(19.9 \%)$ transitioned to $\mathrm{MCI}_{\mathrm{CC}}, 109(16.8 \%)$ transitioned to dementia, 234 (36.1\%) died without dementia, and $92(14.2 \%)$ left the study without dementia. The overall transition structure is described in table 3. Incident dementia required an average of $10.4 \pm 4.4$ transitions to develop. The observed number of transitions required for death without dementia $(9.8 \pm 4.4)$ or dropout without dementia $(9.3 \pm 4.5)$ relative to incident dementia underscores the importance of accounting for competing events in modeling dementia risks.

Just over one quarter of the sample reported a head injury $(166 / 649,25.6 \%)$. Men $(83 / 234,35.5 \%)$ reported a higher proportion of head injury than women $(83 / 415,20.0 \%$; $\left.\chi^{2}=18.81, \mathrm{p}<0.0001\right)$. APOE $\varepsilon 4$ carriers were equally distributed among participants with and without a reported injury, both overall $\left(\chi^{2}=0.07, p=0.78\right)$ and by $\operatorname{sex}\left(\operatorname{men}: \chi^{2}=0.2, p=\right.$ 0.65 , women: $\chi^{2}=0.0, p=1.00$ ). Of the 166 participants who reported a history of head injury, 34 transitioned to $\mathrm{MCI}_{\mathrm{CC}}, 27$ transitioned to dementia, and 72 died without transitioning to dementia. The majority of reported injuries occurred prior to baseline $(156 / 166,94.0 \%)$. Most participants reported a single instance of head injury, but some participants reported 2 $(n=15)$ or more $(n=3)$ instances. Five of the 83 men reported that their injuries were 
Abner et al.: Self-Reported Head Injury and Risk of Late-Life Impairment and AD Pathology in an AD Center Cohort

Table 4. Reported sources of head injury by gender and LOC $^{\mathrm{a}}$

\begin{tabular}{|c|c|c|c|c|c|c|}
\hline \multirow[t]{2}{*}{ Source } & \multicolumn{2}{|l|}{ Men } & \multicolumn{2}{|l|}{ Women } & \multicolumn{2}{|l|}{ Total } \\
\hline & $\begin{array}{l}\text { LOC } \\
<5 \text { min }\end{array}$ & $\begin{array}{l}\mathrm{LOC} \\
\geq 5 \mathrm{~min}\end{array}$ & $\begin{array}{l}\text { LOC } \\
<5 \text { min }\end{array}$ & $\begin{array}{l}\text { LOC } \\
\geq 5 \mathrm{~min}\end{array}$ & $\begin{array}{l}\text { LOC } \\
<5 \mathrm{~min}\end{array}$ & $\begin{array}{l}\text { LOC } \\
\geq 5 \text { min }\end{array}$ \\
\hline Sports and recreation & 22 & 7 & 9 & 2 & 31 & 9 \\
\hline Automobile accident & 9 & 10 & 22 & 8 & 31 & 18 \\
\hline Fall & 7 & 5 & 15 & 7 & 22 & 12 \\
\hline Interpersonal violence & 5 & 2 & 2 & 0 & 7 & 2 \\
\hline Other blow to the head ${ }^{b}$ & 8 & 2 & 7 & 0 & 15 & 2 \\
\hline Not described & 8 & 1 & 12 & 2 & 20 & 3 \\
\hline
\end{tabular}

${ }^{\text {a }}$ Cell entries reflect number of unique participants reporting the source.

${ }^{\mathrm{b}}$ For example being struck by falling objects, striking head on ceilings or walls.

sustained during military service, but in general veteran status was unknown. Men tended to have injuries resulting in LOC of at least 5 min more frequently than women (table 4), though the difference was not statistically significant (31.3 vs. $21.7 \% ; \chi^{2}=1.98, p=0.16$ ). However, a logistic regression model adjusted for the cause of the injury (table 4) revealed that among participants who reported a head injury, men had significantly increased odds of LOC of at least 5 min compared to women. This was observed whether the cases with an unknown source were excluded from $(\mathrm{OR}=2.55,95 \% \mathrm{CI} 1.11-5.87)$ or included in $(\mathrm{OR}=2.26,95 \% \mathrm{CI}$ 1.04-4.92) the model.

The interaction between head injury and sex was not significant and was not retained (see table 5 for final fitted model estimates). Head injury, without respect to age, was a significant risk for the one-step transition from a transient state to death without dementia (OR = $1.54,95 \%$ CI 1.12-2.13). The interaction between head injury and age was significant for the one-step transitions from normal cognition, $\mathrm{aMCI}_{\mathrm{TB}}$, or $\mathrm{mMCI}_{\mathrm{TB}}$ to $\mathrm{MCI}_{\mathrm{CC}}(\mathrm{p}=0.017)$ and for the one-step transition from $\mathrm{MCI}_{\mathrm{CC}}$ to dementia $(\mathrm{p}=0.0069)$. For a 1-year increase in age, the $\mathrm{OR}$ for the transition from normal cognition, $\mathrm{aMCI}_{\mathrm{TB}}$, or $\mathrm{mMCI}_{\mathrm{TB}}$ to $\mathrm{MCI}_{\mathrm{CC}}$ for participants with a history of head injury was 1.21 (95\% CI 1.15-3.56) and the OR for the transition from $\mathrm{MCI}_{\mathrm{CC}}$ to dementia was 1.34 (95\% CI 1.11-1.61). Model results may also be used to estimate the expected number of one-step transitions required to reach the absorbing states [24]. In this cohort, self-reported head injury decreased the time to dementia by approximately 6 months.

Finally, sensitivity analyses were conducted to assess the effect of excluding participants whose head injuries occurred after baseline $(n=10)$ and excluding participants whose head injuries occurred less than 10 years prior to their first diagnosis of clinical dementia $(n=4)$. All 3 models produced a similar fit (data not shown), and conclusions did not change. Additional sensitivity analyses tested whether the effect of head injury on transition risks varied by prior state. These interactions were not significant.

\section{Pathological Data}

Among the 270 participants who died and underwent autopsy, 82 (30.4\%) reported a history of head injury. Fifteen of the $82(18.3 \%)$ were clinically demented at death and received neuropathological diagnoses as follows: $A D(n=6)$, cerebrovascular disease $(n=1)$, $A D+$ dementia with Lewy bodies $(n=2), A D+$ cerebrovascular disease $(n=2)$, hippocampal sclerosis + cerebrovascular disease $(n=1)$, cerebrovascular disease $+A D+$ hippocampal sclerosis $(n=1), A D+$ dementia with Lewy bodies + cerebrovascular disease + hippocampal scle- 
Table 5. Multistate Markov chain results for risk factors affecting transitions from transient states or $\mathrm{MCI}_{\mathrm{CC}}$ to dementia and death without dementia

\begin{tabular}{|c|c|c|c|c|}
\hline Parameter & Risk comparison & OR & $95 \% \mathrm{CI}$ & $\mathrm{p}$ \\
\hline \multicolumn{5}{|l|}{$\mathrm{T} \rightarrow \mathrm{aMCI}_{\mathrm{TB}}$} \\
\hline Age & 1-year difference & 1.03 & $1.02-1.04$ & $<0.0001$ \\
\hline Sex & Female vs. male & 0.79 & $0.66-0.93$ & 0.0056 \\
\hline Prior $=\mathrm{aMCI}_{\mathrm{TB}}$ & $\mathrm{aMCI}_{\mathrm{TB}}$ vs. normal & 1.27 & $1.03-1.58$ & 0.0277 \\
\hline Prior $=\mathrm{mMCI}_{\mathrm{TB}}$ & $\mathrm{mMCI}_{\mathrm{TB}}$ vs. normal & 0.77 & $0.59-1.01$ & 0.0561 \\
\hline \multicolumn{5}{|l|}{$\mathrm{T} \rightarrow \mathrm{mMCI}_{\mathrm{TB}}$} \\
\hline Age & 1-year difference & 1.07 & $1.06-1.09$ & $<0.0001$ \\
\hline Education & $\leq 12$ years vs. $>12$ years & 1.70 & $1.38-2.10$ & $<0.0001$ \\
\hline Prior $=\mathrm{aMCI}_{\mathrm{TB}}$ & $\mathrm{aMCI}_{\mathrm{TB}}$ vs. normal & 1.06 & $0.84-1.34$ & 0.6473 \\
\hline Prior $=\mathrm{mMCI}_{\mathrm{TB}}$ & $\mathrm{mMCI}_{\mathrm{TB}}$ vs. normal & 4.78 & $3.93-5.81$ & $<0.0001$ \\
\hline \multicolumn{5}{|l|}{$\mathrm{T} \rightarrow \mathrm{MCI}_{\mathrm{CC}}$} \\
\hline Family history & Present vs. absent & 1.42 & $1.11-1.83$ & 0.0063 \\
\hline APOE $\varepsilon 4$ & Present vs. absent & 1.85 & $1.27-2.69$ & 0.0014 \\
\hline Age $\times$ head injury & $\begin{array}{l}\text { 1-year difference in age when } \\
\text { head injury is present }\end{array}$ & 1.21 & $1.15-3.56$ & 0.0173 \\
\hline Prior = $\mathrm{aMCI}_{\mathrm{TB}}$ & $\mathrm{aMCI}_{\mathrm{TB}}$ Vs. normal & 2.20 & $1.29-3.75$ & 0.0038 \\
\hline Prior $=\mathrm{mMCI}_{\mathrm{TB}}$ & $\mathrm{mMCI}_{\mathrm{TB}}$ vs. normal & 5.86 & $3.81-9.00$ & $<0.0001$ \\
\hline \multicolumn{5}{|l|}{$\mathrm{T} \rightarrow$ dementia } \\
\hline Age & 1-year difference & 1.18 & $1.13-1.23$ & $<0.0001$ \\
\hline APOE $\varepsilon 4$ & Present vs. absent & 2.58 & $1.52-4.38$ & 0.0005 \\
\hline Prior $=\mathrm{aMCI}_{\mathrm{TB}}$ & $\mathrm{aMCI}_{\mathrm{TB}}$ vs. normal & 2.24 & $0.97-5.17$ & 0.0596 \\
\hline Prior $=\mathrm{mMCI}_{\mathrm{TB}}$ & $\mathrm{mMCI}_{\mathrm{TB}}$ vs. normal & 7.65 & $4.08-14.34$ & $<0.0001$ \\
\hline \multicolumn{5}{|l|}{$\mathrm{T} \rightarrow$ death } \\
\hline Age & 1-year difference & 1.19 & $1.16-1.22$ & $<0.0001$ \\
\hline$<1-10$ pack-years & $<1-10$ pack-years vs. never smoked & 1.16 & $0.68-1.96$ & 0.5914 \\
\hline $10-20$ pack-years & $10-20$ pack-years vs. never smoked & 1.20 & $0.65-2.22$ & 0.5566 \\
\hline$\geq 20$ pack-years & $\geq 20$ pack-years vs. never smoked & 2.05 & $1.49-2.83$ & $<0.001$ \\
\hline Hypertension & Present vs. absent & 1.46 & $1.08-1.96$ & 0.0133 \\
\hline Head injury & Present vs. absent & 1.54 & $1.12-2.13$ & 0.0089 \\
\hline Prior $=\mathrm{aMCI}_{\mathrm{TB}}$ & $\mathrm{aMCI}_{\mathrm{TB}}$ vs. normal & 0.72 & $0.43-1.19$ & 0.1980 \\
\hline Prior $=\mathrm{mMCI}_{\mathrm{TB}}$ & $\mathrm{mMCI}_{\mathrm{TB}}$ vs. normal & 2.60 & $1.85-3.64$ & $<0.0001$ \\
\hline \multicolumn{5}{|l|}{$\mathrm{T} \rightarrow$ dropout } \\
\hline Age & 1-year difference & 1.06 & $1.02-1.09$ & 0.0008 \\
\hline Hypertension & Present vs. absent & 1.90 & $1.20-3.00$ & 0.0060 \\
\hline Prior $=\mathrm{aMCI}_{\mathrm{TB}}$ & $\mathrm{aMCI}_{\mathrm{TB}}$ vs. normal & 1.49 & $0.77-2.89$ & 0.2324 \\
\hline Prior $=\mathrm{mMCI}_{\mathrm{TB}}$ & $\mathrm{mMCI}_{\mathrm{TB}}$ vs. normal & 1.98 & $1.77-2.22$ & $<0.0001$ \\
\hline \multicolumn{5}{|l|}{$\mathrm{MCI}_{\mathrm{CC}} \rightarrow$ dementia } \\
\hline$<1-10$ pack-years & $<1-10$ pack-years vs. never smoked & 0.28 & $0.08-0.94$ & 0.0388 \\
\hline $10-20$ pack-years & $10-20$ pack-years vs. never smoked & 0.27 & $0.07-1.09$ & 0.0654 \\
\hline$\geq 20$ pack-years & $\geq 20$ pack-years vs. never smoked & 0.31 & $0.13-0.71$ & 0.0054 \\
\hline Age $\times$ head injury & $\begin{array}{l}\text { 1-year difference in age when head } \\
\text { injury is present }\end{array}$ & 1.34 & $1.11-1.61$ & 0.0069 \\
\hline \multicolumn{5}{|l|}{$\mathrm{MCI}_{\mathrm{CC}} \rightarrow$ death } \\
\hline Age & 1-year difference & 1.12 & $1.04-1.20$ & 0.0023 \\
\hline
\end{tabular}


Abner et al:: Self-Reported Head Injury and Risk of Late-Life Impairment and AD Pathology in an AD Center Cohort

Table 6. Characteristics of autopsied participants from the BRAiNS cohort by gender and history of lifetime head injury $(\mathrm{n}=238)$

\begin{tabular}{|c|c|c|c|c|}
\hline & \multicolumn{2}{|l|}{ Men } & \multicolumn{2}{|l|}{ Women } \\
\hline & $\begin{array}{l}\text { head injury } \\
(n=36)\end{array}$ & $\begin{array}{l}\text { no head injury } \\
(\mathrm{n}=61)\end{array}$ & $\begin{array}{l}\text { head injury } \\
(n=34)\end{array}$ & $\begin{array}{l}\text { no head injury } \\
(\mathrm{n}=107)\end{array}$ \\
\hline Age at death, years & $84.4 \pm 6.9$ & $86.9 \pm 7.0$ & $86.0 \pm 8.0$ & $87.1 \pm 7.5$ \\
\hline Final MMSE score & $26.4 \pm 4.5$ & $25.8 \pm 4.3$ & $27.5 \pm 3.5$ & $24.4 \pm 7.7$ \\
\hline Education, years & $16.2 \pm 2.6$ & $16.7 \pm 2.8$ & $15.3 \pm 2.3$ & $15.7 \pm 2.0$ \\
\hline APOE $\varepsilon 4$ positive & 22.2 & 39.3 & 20.6 & 28.0 \\
\hline CAA positive & 63.9 & 54.1 & 48.4 & 52.3 \\
\hline $\mathrm{AD}$ & 27.8 & 26.2 & 14.7 & 34.6 \\
\hline \multicolumn{5}{|l|}{ Braak stage } \\
\hline $0-$ II & 38.9 & 52.5 & 64.7 & 46.7 \\
\hline III-IV & 44.4 & 34.4 & 26.5 & 30.8 \\
\hline V-VI & 16.7 & 13.1 & 8.8 & 22.4 \\
\hline \multicolumn{5}{|l|}{ CERAD rating } \\
\hline No & 36.1 & 49.2 & 52.9 & 43.0 \\
\hline Possible AD & 11.1 & 11.5 & 11.8 & 8.4 \\
\hline Probable AD & 33.3 & 26.2 & 20.6 & 24.3 \\
\hline Definite AD & 19.4 & 13.1 & 14.7 & 24.3 \\
\hline
\end{tabular}

Values are means \pm SD or percentages. $C A A=$ Cerebral amyloid angiopathy.

rosis $(n=1)$, and dementia with Lewy bodies $(n=1)$. Of the 238 participants with quantitative neuropathological data, 70 (29.4\%) reported a history of head injury (table 6).

Men with a history of head injury had higher mean parietal and occipital DPs and more NPs in all neocortical areas than men without ( $p<0.05$; fig. 2). Women with a history of head injury did not have significantly higher neocortical DPs or NPs than women (or men) without a head injury (fig. 2). Additional analyses were performed to determine if age at injury or source of injury mitigated the observed head injury by sex interaction; the conclusions did not change (data not shown). Mean neocortical NFTs were not associated with a history of head injury (fig. 2).

The pathological burden in the medial temporal structures, except for the entorhinal cortex, was not significantly increased by a history of head injury. Men who reported a history of head injury had significantly increased DPs $(20.6 \pm 2.3$ vs. $13.4 \pm 1.8, p=0.0072)$ and NPs $(3.8 \pm 0.7$ vs. $1.6 \pm 0.6, p=0.013)$ in the entorhinal cortex compared to men who did not. NFTs in the entorhinal cortex were unaffected (data not shown).

When the analysis was restricted to the 39 cases ( 31 without head injury, 8 with head injury) who received a clinical diagnosis of dementia, evaluation of the sex by head injury interaction was not adequately powered. No statistically significant differences were observed between dementia cases with and without head injury after controlling for APOE $\varepsilon 4$, sex, age at death, and cerebral amyloid angiopathy. Further restricting the analysis to men with dementia ( 5 with head injury, 10 without) reveals that a history of head injury is marginally significantly associated with increased DPs in the frontal ( $47.7 \pm 6.2 \mathrm{vs} .34 .0 \pm 4.3, \mathrm{p}=0.097$ ) and occipital ( $35.0 \pm 5.7$ vs. $21.7 \pm 4.0, p=0.081$ ) lobes and NPs in the occipital lobe (23.8 \pm 4.7 vs. $11.6 \pm 3.3, \mathrm{p}=0.055)$.

While mean NFTs, unlike neocortical DPs and NPs, were not elevated among men with a history of head injury, the odds of AD-positive pathology were again significantly increased for men with a history of head injury (OR $=1.47,95 \%$ CI 1.03-2.09) but not women (OR = 

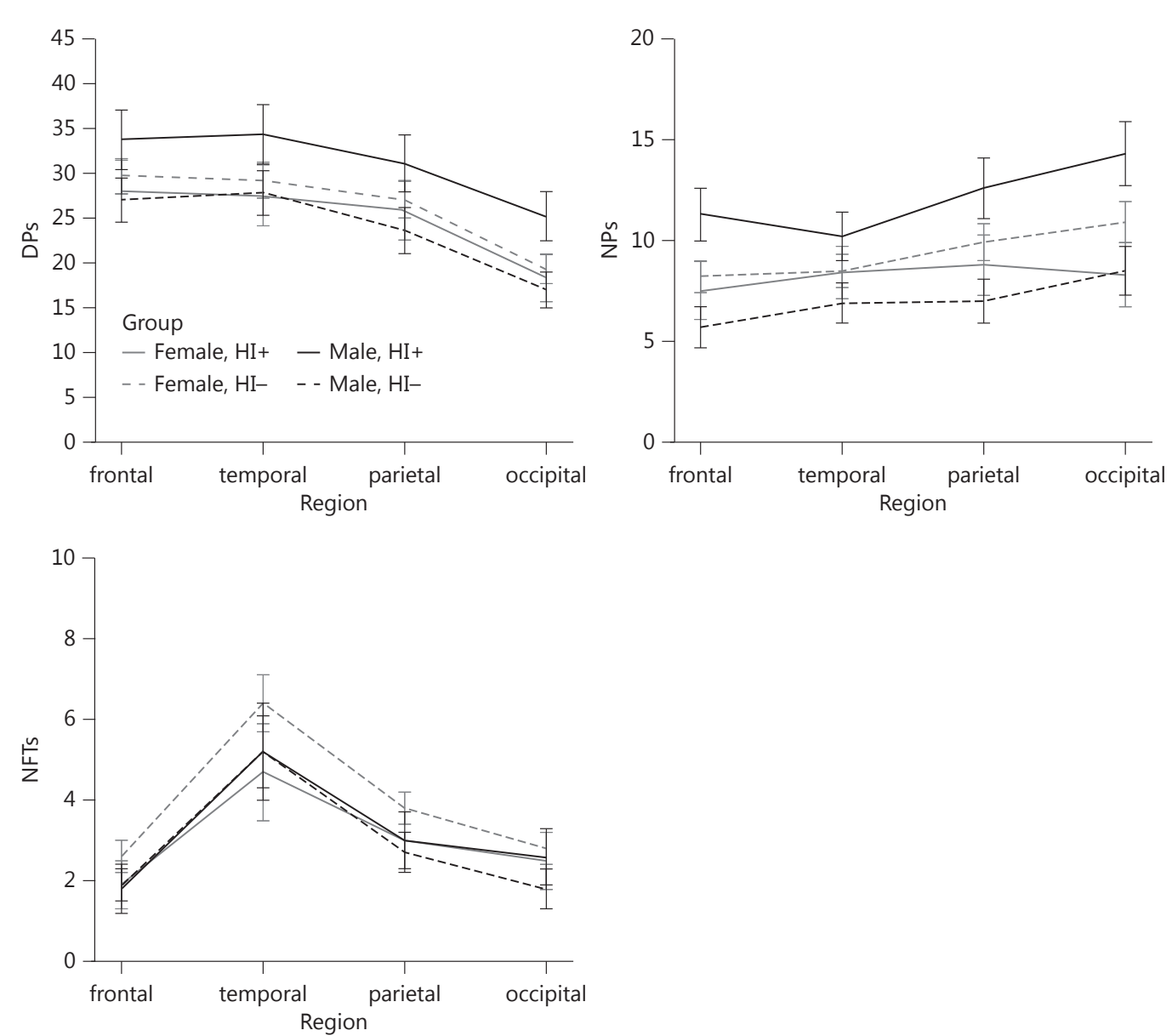

Fig. 2. Estimated mean number of DPs, NPs, and NFTs by neocortical region; whiskers are SEM $(n=238)$. The final MANCOVA models included main effects for age at death, clinical dementia status, APOE $\varepsilon 4$, cerebral amyloid angiopathy, and an interaction term and main effects for head injury (HI) and male gender.

$1.18,95 \%$ CI $0.83-1.68)$. This apparent conflict may result from the fact that $61.1 \%$ of men with a head injury had a Braak stage of at least III compared to $47.5 \%$ of men without a head injury. However, even among men with Braak stage III or higher, mean neocortical NFTs were not associated with a history of head injury $(\mathrm{p}>0.5)$.

\section{Discussion}

Clinical and neuropathological data from participants in a longitudinal study of aging and cognition $(n=649)$ were analyzed to assess the effects of self-reported head injury. Our results support prior work identifying increased risk of cognitive impairment [35], earlier onset of dementia [20,21] as well as increased risk of mortality with head injury [15]. Although the 6-month reduction in time to dementia onset we report is much less than the 8 years in the Olmstead County study [20], differences in study design, head injury case definition, study population, and clinical diagnosis could account for the discrepancy. We also found an unexpected correlation between head injury, gender, and increased AD neuropathological changes. 
Abner et al.: Self-Reported Head Injury and Risk of Late-Life Impairment and AD Pathology in an AD Center Cohort

The effect of head injury on dementia risk may be modified not only by age at injury and severity of injury (or injuries) but also by other factors including gender and APOE $\varepsilon 4$ status [36]. We note that while a single injury of sufficient severity can increase the risk of manifesting clinical dementia, it does not follow necessarily that these events lead to the specific features of AD. In experimental studies (i.e., animal studies), however, evidence of long-term neurodegeneration was observed after a single head injury, and accelerated $\beta$-amyloid peptide deposition and cognitive impairment was observed after repeated mild head injury [37]. Thus, animal models have provided hypothesized mechanistic links between head injury and $A D$, and autopsy-based case series of head injury have also suggested a link between head injury and $\mathrm{AD}$-promoting and $\mathrm{AD}$-like pathology [3, 37-39].

Detailed neuropathological data were available on over one third of the study participants. A history of self-reported head injury was associated with increased levels of amyloid plaque deposition in the neocortex and entorhinal cortex, as well as increased odds of AD pathology for men but not for women, which supports prior clinical studies. Fleminger et al. [13] posited that women may be protected from the deleterious effects of head injury by the presence of female sex hormones. Indeed, the women who came to autopsy in the current study were more likely to report two instances of LOC (6/34 vs. $1 / 36, p=0.027$, Fisher's exact test) and were more likely to have sustained a head injury after age $55(16 / 34$ vs. $7 / 36, p=$ 0.030 , Fisher's exact test). If $A D$ pathology was more affected by more recent or frequent LOC, it should follow that the women, not the men, would have elevated plaque counts in association with exposure to head injury.

An alternative explanation is that male gender may be a proxy for severity, repetition, poor reporting, and particular mechanisms (e.g. contact sports) of brain injury. Men in our study tended to report injuries that led to LOC $\geq 5$ min more often than women, which suggests that their injuries may have been more severe overall. Plassman et al. [18] found increased risk of both all-cause dementia and AD for veterans with moderate and severe but not mild injuries, and Schofield et al. [21] found an increased risk of AD for participants who reported head injuries with LOC $\geq 5$ min but not $<5 \mathrm{~min}$. Of the 36 autopsied men with a history of head injury, 13 (36\%) reported sports and recreation as the source of the injury, 9 of which were identified as football or boxing. It may be that while the participant reported only one or two instances of head injury where LOC occurred, multiple instances of injury were actually experienced without LOC. Chronic effects of head injury may be due to lifetime cumulative exposure rather than an acute single event [40]. Recent data reveal an increased risk of AD for retired professional American football players, who are assumed to have been exposed to repeated blows to the head, relative to the general US population (standardized morbidity ratio $=3.29$, 95\% CI 1.55-7.95) [41].

We note that the reported head trauma is usually quite remote from study enrollment, in some cases occurring in infancy; however, these injuries could still affect the brain chronically [3]. In addition to the influence of recall bias implicit in the study design, participants in the current study are highly educated compared to their peers, with $65.7 \%$ having at least a Bachelor's degree versus $24.5 \%$ of those over the age of 60 years nationally [42]. If, as Moretti et al. [35] suggest, cognitive reserve is the best predictor of cognitive outcome and decline following head injury, our participants may have been less vulnerable to its effects.

As for the neuropathology, head injury severity occurs along a spectrum, and coding such injuries dichotomously obscures relevant information [43]. Recovery (and wound repair capacity of an individual) may also be graded on a continuum, and all these factors may influence the long-term sequelae of the injury [43]. Future studies of head injury as a risk for dementia and AD should consider collecting detailed data on severity, anatomical location, posttraumatic amnesia, and receipt of treatment if possible. Furthermore, it must be emphasized that the neuropathological data reported here are descriptive rather than experimental. 
Abner et al.: Self-Reported Head Injury and Risk of Late-Life Impairment and AD Pathology in an AD Center Cohort

For example, it is possible that imposing a matched case-control design on the autopsied cases would yield different results.

Despite the limitations inherent in the data, multiple studies have found that even a single reported occurrence of head injury is associated with increased risk of incident dementia years or decades later. Although such knowledge may not be useful to those individuals for whom head injury is not a modifiable risk factor (i.e., having already sustained one), it does underscore the necessity of taking proper precautions for those involved in professions and recreational activities where head injury is common.

\section{Acknowledgements}

We thank the participants and their families, as well as the University of Kentucky Alzheimer's Disease Center staff members. This work was supported by grants to the University of Kentucky's Sanders-Brown Center on Aging from the National Institute on Aging (grant No. R01 AG038651, R01 AG019241, and P30 AG028383), as well as a grant from the National Center for Advancing Translational Sciences to the University of Kentucky's Center for Clinical and Translational Science (grant No. UL1TR000117). The NIA did not play any role in the study design, in the collection, analysis, and interpretation of data, in the writing of the paper, or in the decision to submit the article for publication. The authors submitted the manuscript independent of funding sources.

\section{References}

1 Beach TG, Monsell SE, Phillips LE, Kukull W: Accuracy of the clinical diagnosis of Alzheimer disease at National Institute on Aging Alzheimer Disease Centers, 2005-2010. J Neuropathol Exp Neurol 2012;71:266-273.

- 2 McKenzie JE, Gentleman SM, Roberts GW, Graham DI, Royston MC: Increased number of $\beta$ APP-immunoreactive neurones in the entorhinal cortex after head injury. Neuroreport 1994;6:161-164.

3 Johnson VE, Stewart W, Smith DH: Widespread tau and amyloid-beta pathology many years after a single traumatic brain injury in humans. Brain Pathol 2011;22:142-149.

- 4 Johnson VE, Stewart JE, Begbie FD, Trojanowski JQ, Smith DH, Stewart W: Inflammation and white matter degeneration persist for years after a single traumatic brain injury. Brain 2013;136:28-42.

5 Chen X-H, Johnson VE, Uryu K, Trojanowski JQ, Smith DH: A lack of amyloid $\beta$ plaques despite persistent accumulation of amyloid $\beta$ in axons of long-term survivors of traumatic brain injury. Brain Pathol 2009;19:214223.

6 Uryu K, Chen X-H, Martinez D, Browne KD, Johnson VE, Graham DI, et al: Multiple proteins implicated in neurodegenerative diseases accumulate in axons after brain trauma in humans. Exp Neurol 2007;208:185-192.

7 Corsellis JAN, Bruton CJ, Freeman-Browne D: The aftermath of boxing. Psychol Med 1973;3:270-303.

- 8 McKee AC, Stein TD, Nowinski CJ, Stern RA, Daneshvar DH, Alvarez VE, et al: The spectrum of disease in chronic traumatic encephalopathy. Brain 2013;136:43-64.

$\checkmark 9$ Geddes JF, Vowles GH, Nicoll JAR, Revesz T: Neuronal cytoskeletal changes are an early consequence of repetitive head injury. Acta Neuropathol 1999;98:171-178.

$\checkmark 10$ Forstl H, Haass C, Hemmer B, Meyer B, Halle M: Boxing - Acute complications and late sequelae. Dtsch Arztebl Int 2010;107:835-839.

11 Saing T, Dick M, Nelson PT, Kim RC, Cribbs DH, Head E: Frontal cortex neuropathology in dementia pugilistica. J Neurotrauma 2012;29:1054-1070.

-12 Kondo K, Niino M, Shido K: A case-control study of Alzheimer's disease in Japan - Significance of life-styles. Dementia 1994;5:314-326.

13 Fleminger S, Oliver DL, Lovestone S, Rabe-Hesketh S, Giora A: Head injury as a risk factor for Alzheimer's disease: the evidence 10 years on; a partial replication. J Neurol Neurosurg Psychiatry 2003;74:857-862.

14 Mehta KM, Ott A, Kalmijn S, Slotter A, van Duijn CM, Hofman A, et al: Head trauma and risk of dementia and Alzheimer's disease: the Rotterdam Study. Neurology 1999;53:1959-1962.

$>15$ Dams-O'Connor K, Gibbons LE, Bowen JD, McCurry SM, Larson EB, Crane PK: Risk for late-life re-injury, dementia and death among individuals with traumatic brain injury: a population-based study. J Neurol Neurosurg Psychiatry 2013;84:177-182.

-16 Sundström A, Nilsson LG, Cruts M, Adolfsson R, Van Broeckhoven C, Nyberg L: Increased risk of dementia following mild head injury for carriers but not for non-carriers of the APOE epsilon4 allele. Int Psychogeriatr 2007;19:159-165.

17 Brayne C, Gill C, Huppert FA, Barkley C, Gehlhaar E, Girling DM, O'Connor DW, Paykel ES: Vascular risks and incident dementia: results from a cohort study of the very old. Dement Geriatr Cogn Disord 1998;9:175-180. 
Abner et al.: Self-Reported Head Injury and Risk of Late-Life Impairment and AD

Pathology in an AD Center Cohort

18 Plassman BL, Havlik RJ, Steffens DC, Helms MJ, Newman TN, Drosdick D, et al: Documented head injury in early adulthood and risk of Alzheimer's disease and other dementias. Neurology 2000;55:1158-1166.

19 Williams DB, Annegers JF, Kokmen E, O’Brien PC, Kurland LT: Brain injury and neurologic sequelae: a cohort study of dementia, parkinsonism, and amyotrophic lateral sclerosis. Neurology 1991;41:1554-1557.

20 Nemetz PN, Leibson C, Naessens JM, Beard M, Kokmen E, Annegers JF, et al: Traumatic brain injury and time to onset of Alzheimer's disease: a population-based study. Am J Epidemiol 1999;149:32-40.

-21 Schofield PW, Tang M, Marder K, Bell K, Dooneief G, Chun M, et al: Alzheimer's disease incidence after remote head injury: an incidence study. J Neurol Neurosurg Psychiatry 1997;62:119-124.

22 Schmitt FA, Nelson PT, Abner E, Scheff S, Jicha GA, Smith C, et al: University of Kentucky Sanders-Brown healthy brain aging volunteers: donor characteristics, procedures and neuropathology. Curr Alzheimer Res 2012;9:724-733.

23 Abner EL, Kryscio RJ, Cooper GE, Fardo DW, Jicha GA, Mendiondo MS, et al: Mild cognitive impairment: statistical models of transition using longitudinal clinical data. Int J Alzheimers Dis 2012;2012:291920.

24 Kryscio RJ, Schmitt FA, Salazar JC, Mendiondo MS, Markesbery WR: Risk factors for transitions from normal to mild cognitive impairment and dementia. Neurology 2006;66:828-832.

-25 Salazar JC, Schmitt FA, Yu L, Mendiondo MM, Kryscio RJ: Shared random effects analysis of multi-state Markov models: application to a longitudinal study of transitions to dementia. Stat Med 2007;26:568-580.

-26 Yu L, Griffith WS, Tyas SL, Snowdon DA, Kryscio RJ: A nonstationary Markov transition model for computing the relative risk of dementia before death. Stat Med 2010;29:639-648.

27 Murphy TE, Han L, Allore HG, Peduzzi PN, Gill TM, Lin H: Treatment of death in the analysis of longitudinal studies of gerontological outcomes. J Gerontol A Biol Sci Med Sci 2011;6:109-114.

28 Morris J, Weintraub S, Chui HC, Cummings J, DeCaril C, Ferris S, et al: The Uniform Data Set (UDS): clinical and cognitive variables and descriptive data from Alzheimer Disease Centers. Alzheimer Dis Assoc Disord 2006; 20:210-216.

29 American Psychiatric Association: Diagnostic and Statistical Manual of Mental Disorders, ed 4. Washington, American Psychiatric Association, 1994.

30 SAS Institute Inc: SAS/STAT ${ }^{\circledR} 9.3$ Procedures Guide. Cary, SAS Institute Inc, 2011.

-31 Gentleman SM, Graham DI, Roberts GW: Molecular pathology of head trauma: altered $\beta A P P$ metabolism and the aetiology of Alzheimer's disease. Prog Brain Res 1993;96:237-246.

-32 Mirra SS, Heyman A, McKeel DW, Sumi SM, Crain BR, Brownlee LM: The Consortium to Establish a Registry for Alzheimer's Disease (CERAD). 2. Standardization of the neuropathologic assessment of Alzheimer's disease. Neurology 1991;41:479-486.

33 Nelson PT, Jicha GA, Schmitt FA, Liu H, Davis DG, Mendiondo MS, et al: Clinicopathologic correlations in a large Alzheimer Disease Center autopsy cohort: neuritic plaques and neurofibrillary tangles 'do count' when staging disease severity. J Neuropathol Exp Neurol 2007;66:1136-1146.

-34 Davis DG, Schmitt FA, Wekstein DR, Markesbery WR: Alzheimer neuropathologic alterations in age cognitively normal individuals. J Neuropathol Exp Neurol 1999;58:376-388.

-35 Moretti L, Cristofori I, Weaver SM, Chau A, Portelli JN, Grafman J: Cognitive decline in older adults with a history of traumatic brain injury. Lancet Neurol 2012;11:1103-1112.

36 Jellinger K: Head injury and dementia. Curr Opin Neurol 2004;17:719-723.

37 Uryu K, Laurer H, MacIntosh T, Practico D, Martinez D, Leight S, et al: Repetitive mild brain trauma accelerates $\mathrm{AB}$ deposition, lipid peroxidation, and cognitive impairment in a transgenic mouse model of Alzheimer amyloidosis. J Neurosci 2002;22:446-454.

-38 Johnson VE, Stewart W, Smith DH: Axonal pathology in traumatic brain injury. Exp Neurol 2013;246:35-43.

-39 Johnson VE, Stewart W, Smith DH: Traumatic brain injury and amyloid- $\beta$ pathology: a link to Alzheimer's disease? Nat Rev Neurosci 2010;11:361-370.

40 Dashnaw ML, Petraglia AL, Bailes JE: An overview of the basic science of concussion and subconcussion: where we are and where we are going. Neurosurg Focus 2012;33:E5.

-41 Lehman EJ, Hein MJ, Baron SL, Gersic CM: Neurodegenerative causes of death among retired National Football League players. Neurology 2012;79:1970-1974.

42 United States Census Bureau: 2011 American Community Survey. Washington, United States Census Bureau, 2011.

43 Iverson G: Mild traumatic brain injury and risk for Alzheimer's disease. Int Brain Injury Assoc 2006;4. http:// www.internationalbrain.org/articles/mild-traumatic-brain-injury-risk-for-alzheimers-disease/ (accessed September 28, 2012). 